after cardiac bypass operation and patients with adult respiratory distress syndrome have also been found to have a measurable and significant lung $\mathrm{Vo}_{2}{ }^{3,4}$ This method, however, engenders the potential error of underestimating $\mathrm{Vo}_{2}$ Fick by neglecting the bronchial circulation, which is known to have increased flow during inflammatory lung disorders. Our patient therefore provided an unique opportunity to measure true lung $\mathrm{Vo}_{2}$ because the bronchial circulation had been interrupted with the double-lung transplant and venous-arterial ECMO at the high flow rate eliminated pulmonary blood flow. In effect, we had a nonperfused lung in vivo, and any measured oxygen consumption at the mouth therefore represented true lung $\mathrm{VO}_{2}$.

The measured lung $\mathrm{VO}_{2}$ our patient is probably higher than normal because the lungs had obvious reperfusion injury. The actual value therefore may reflect increased metabolic activity during inflammation, or, alternatively, $\mathrm{VO}_{2}$ for nonoxidative purposes (e.g., oxygen radical formation). We presume that if the latter were true there would be no corresponding increase in carbon dioxide production, and RQ therefore would fall. The calculated RQ was high, however, especially during conditions of no pulmonary blood flow. This $\mathrm{RQ}$ probably reflected the presence of anaerobic metabolism leading to metabolic acidosis and an increase in $\mathrm{VcO}_{2}$ from bicarbonate buffering of lactic acid (gas- exchange threshold) ${ }^{5}$ The potential anaerobic conditions in double-lung transplants that result from high-flow venous-arterial ECMO support without pulmonary blood flow have been a source of concern because they may lead to ischemic injury to the anastomosis site.
In summary, we have demonstrated the first direct measurement of human lung $\mathrm{VO}_{2}$ in vivo for lungs with reperfusion injury.

\section{REFERENCES}

1. Date H, Matsumura A, Manchester JK, Cooper JM, Lowry $\mathrm{OH}$, Cooper JD. Changes in alveolar oxygen and carbon dioxide concentration and oxygen consumption during lung preservation. The maintenance of aerobic metabolism during lung preservation. J Thorac Cardiovasc Surg 1993; 105:492-501.

2. Weder W, Harper BD, Shimokawa S, et al. Influence of intraalveolar oxygen concentration on lung preservation in a rabbit model. J THORAC Cardiovasc SURG 1991;101:1037-43.

3. Takala J, Keinanen O, Vaisanen P, Kari A. Measurement of gas exchange in intensive care: laboratory and clinical validation of a new device. Crit Care Med 1989;17:1041-7.

4. Gill RS, Cunningham DG, Sharpe MD. Oxygen consumption in sepsis: contribution of the lung [Abstract]. Am J Respir Crit Care Med 1994;149:A414.

5. Patessio A, Casaburi R, Carone M, Appendine L, Donner CF, Wasserman K. Comparison of gas exchange, lactate and lactic acidosis thresholds in patients with chronic obstructive pulmonary disease. An Rev Respir Dis 1993;148:622-6.

\title{
SUPRACLAVICULAR LUNG BIOPSY
}

Francis Robicsek, MD, Charlotte, N.C.

Open lung biopsy, however technically simple, carries a significant degree of postoperative discomfort. Because of the severe underlying disease in most patients, it also carries appreciable surgical morbidity and even mortality. Recently introduced video-assisted thoracoscopic techniques alleviated this problem somewhat, but they certainly did not eliminate it. To significantly decrease postoperative discomfort and shorten recuperation time, we recommend that "supraclavicular technique" described here be considered in patients in whom the apexes of the lung are pathologically involved.

A transverse 5 to $6 \mathrm{~cm}$ incision is made just above the superior margin of either the right or the left clavicle,

From the Department of Thoracic and Cardiovascular Surgery and The Heineman Laboratory for Research, Carolinas Medical Center, Charlotte, N.C.

Accepted for publication May 31, 1995.

J THORAC CARDIOvasC SuRg 1995;110:1765-6

Copyright (C) 1995 by Mosby-Year Book, Inc.

$0022-5223 / 95 \$ 5.00+0 \quad \mathbf{1 2 / 5 4 / 6 6 6 0 3}$ depending on the planned biopsy site. The subcutaneous fat is dissected off, and the anterior scalene muscle is exposed and divided. In this process, careful attention is given to identifying and protecting the phrenic nerve. The subclavian artery is retracted downward, exposing the anterior portion of the first rib. A 3 to $4 \mathrm{~cm}$ segment of the exposed first rib is stripped of its periosteum and resected. At that point, the surgeon will already see the apex of the lung under the cupola of the parietal pleura. The pleural cavity is then entered and the apex of the lung is inspected. Usually there is no difficulty in viewing most, if not the entirety, of the upper lobe. An appropriate site is selected on the lung, grabbed with a forceps, and brought through the surgical incision (Fig. 1). A tissue sample from the lung of appropriate size is then excised, and the excision site is either "tied off" or sutured. A $28 \mathrm{~F}$ rubber catheter is inserted through the surgical incision into the pleural cavity and connected to a water-sealed drainage. The incision is closed layer by layer. If there is no continued air leakage the catheter may be conveniently removed at the end of the procedure after 2 to 3 hours.

Throughout the years we have used this method in 


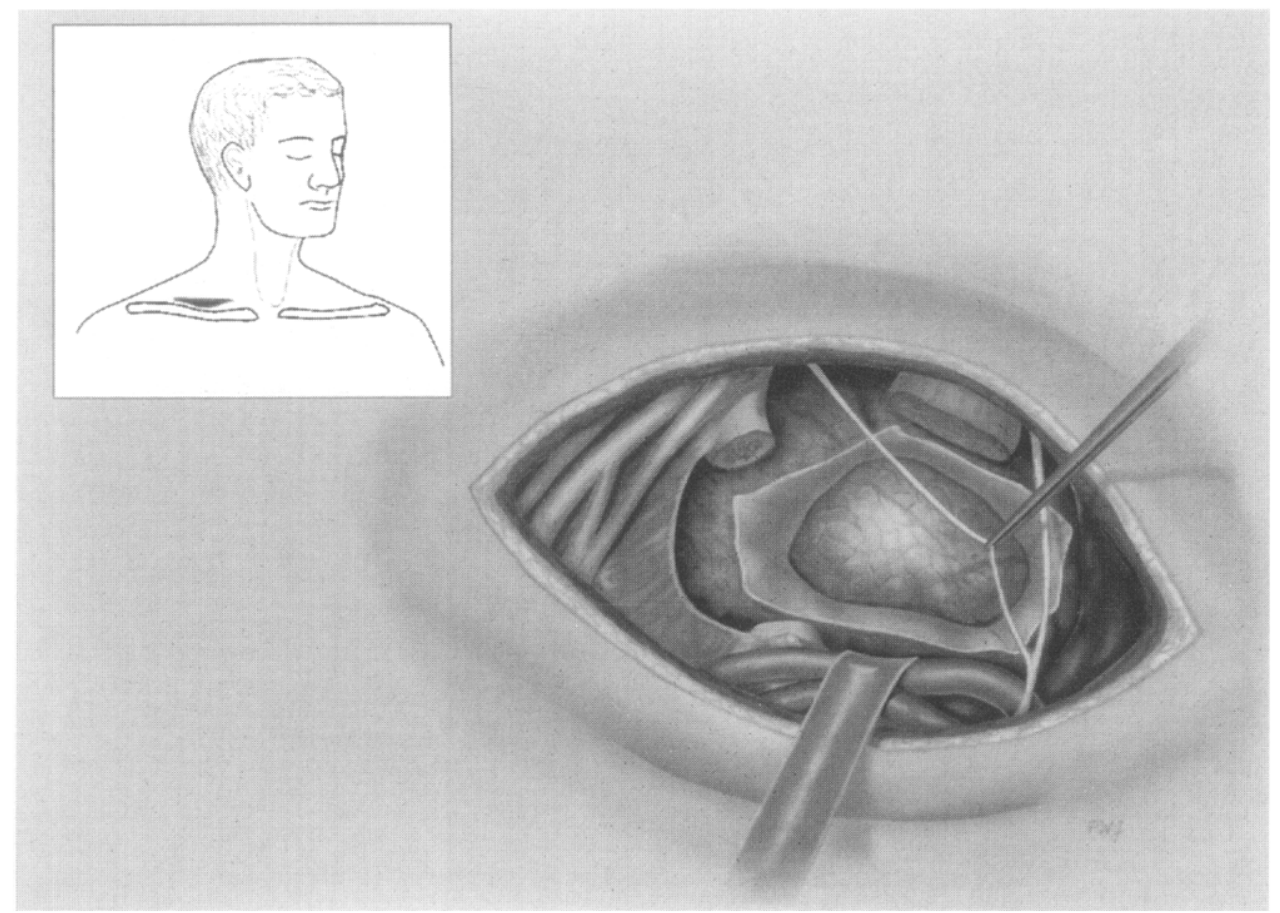

Fig. 1. Supraclavicular exposure of the apex of the lung.

more than a dozen patients in whom open biopsy of the upper portion of the lung was required. We have found the approach to be convenient and well tolerated, even by patients with severe respiratory insufficiency. The disadvantage of the approach is that it traverses an area rich in important anatomic structures. Injury of these structures, especially the phrenic nerve, may be disastrous in patients who already have severely compromised respiratory function. Only surgeons with good knowledge of the anatomy of the thoracic inlet should use this approach.

\section{EXTRACARDIAC MODIFICATION OF THE FONTAN OPERATION WITHOUT USE OF PROSTHETIC MATERIAL}

Jacques A. M. van Son, MD, V. Mohan Reddy, MD, and Frank L. Hanley, MD, San Francisco, Calif.

Since 1992, we have routinely performed the modified Fontan procedure with the use of an extracardiac conduit (nonvalved aortic homograft or polytetrafluoroethylene). ${ }^{1-3 *}$ In this article we describe a technique of extracardiac Fontan operation without use of prosthetic material that is applicable in hearts with L-malposition or L-transposition of the aorta.

From the Division of Cardiothoracic Surgery, UCSF, San Francisco, Calif.

Accepted for publication Jan. 3, 1995.

J THORaC CARdiovasc SuRg 1995;110:1766-8

Copyright (C) 1995 by Mosby-Year Book, Inc.

$0022-5223 / 95 \$ 5.00+0 \quad \mathbf{1 2 / 5 4 / 6 3 0 6 6}$

*Gore-Tex graft, registered trademark of W. L. Gore \& Associates, Inc., Newark, Del.
Case presentation. An 11-year-old boy with situs solitus, double-outlet right ventricle; L-malposition of the aorta, noncommitted ventricular septal defect, severe infundibular and valvular pulmonary stenosis with adequately developed main and branch pulmonary arteries, and bilateral superior venae cavae (SVCs) had been observed since birth. A central aortopulmonary shunt and a left modified Blalock-Taussig shunt had been performed in the past at another hospital. The remote position of the aortic valve relative to the ventricular septal defect and the location of the tricuspid valve precluded a biventricular repair.

A median sternotomy was performed. The main pulmonary artery and its branches and both aortopulmonary shunts were dissected and completely mobilized. After aortic and bicaval cannulation (with the cannula in the inferior vena cava [IVC] placed as low as possible), 